\title{
MULHERES NA POLÍTICA: A PARTICIPAÇÃO DE CANDIDATAS RELIGIOSAS À ALEP (2018)
}

Women in politics: a participation of religious candidates to ALEP (2018)

\author{
Crislaine Pereira de Lima ${ }^{1}$ \\ Cristina Satiê de Oliveira Pátaro ${ }^{2}$ \\ Frank Antonio Mezzomo ${ }^{3}$
}

\section{RESUMO}

A presente pesquisa tem por objetivo analisar a participação de mulheres na campanha eleitoral à Assembleia Legislativa Estadual do Paraná em 2018, atentando-se especificamente às pleiteantes que fizeram uso, em sua campanha, de elementos religiosos. Procuramos evidenciar, a partir dos materiais de campanha que circularam no Facebook oficial das candidatas, a recorrência ao imaginário, símbolos e outros elementos religiosos, sobretudo no que diz respeito às pautas de campanha que evidenciam esta relação entre os campos político e religioso.

Palavras-chave: Mulher. Religião. Política. Campanha Eleitoral.

\begin{abstract}
The present research aims to analyze the participation of women in the electoral campaign to the State Legislative Assembly of Paraná in 2018, paying special attention to the candidate who made use of religious elements in their campaign. We tried to show, from the campaign materials circulated on the official Facebook of the candidates the recurrence of the imaginary, symbols and other religious elements, especially with regard to the campaign guidelines that show this relationship between the political and religious fields.
\end{abstract}

Keywords: Woman. Religion. Politics. Election campaign.

\section{TEMPO DE POLÍTICA: A CAMPANHA ELEITORAL EM UM CONTEXTO GERAL}

\footnotetext{
${ }^{1}$ Graduanda em Pedagogia pela Universidade Estadual do Paraná (Unespar). Bolsista de Iniciação Cientifica CNPq. Universidade Estadual do Paraná - Campus de Campo Mourão. E-mail: criss0713@gmail.com

${ }^{2}$ Doutora em Educação. Professora do Programa de Pós-Graduação Interdisciplinar Sociedade e Desenvolvimento (PPGSeD) da Universidade Estadual do Paraná (Unespar). Universidade Estadual do Paraná - Campus de Campo Mourão. E-mail: crispataro@gmail.com

${ }^{3}$ Doutor em História. Professor do Programa de Pós-Graduação Interdisciplinar Sociedade e Desenvolvimento (PPGSeD) da Universidade Estadual do Paraná (Unespar). Universidade Estadual do Paraná - Campus de Campo Mourão. E-mail: frankmezzomo@gmail.com
} 
“’Candidatas-laranja': a falácia da inclusão de mulheres na política brasileira” JusBrasil, “Candidaturas 'laranjas' de mulheres ligam o alerta da Justiça Eleitoral” - O Globo, “Maioria dos ‘candidatos laranjas’ é mulher” - Estadão. Os exemplos demarcados nas manchetes destacadas evidenciam uma problemática atual que tem rondado os pleitos eleitorais, em especial de 2018, sugerindo a necessidade de pensarmos na participação de mulheres nas eleições. Neste texto, tratamos, especificamente, das eleições para Deputado Estadual do Paraná, na tentativa de apresentar alguns elementos para análise dessa temática.

No Brasil, a participação das mulheres se intensificou na política não por acaso, já que na década de 1990 ocorreu um movimento de abertura e legitimação de um espaço ocupado quase exclusivamente por homens. Se hoje ainda temos desigualdades de gênero em diversos espaços sociais, na política se destaca um avanço, ainda que sutil, da representatividade das mulheres, ao menos no que diz respeito à obrigatoriedade de uma cota de gênero entre os/as pleiteantes.

Neste sentido, é válido considerar alguns dos marcos importantes desse processo, como o Decreto 21.076, de 24/02/1932, assinado por Getúlio Vargas, que em seu artigo $2^{\circ}$ designava os eleitores brasileiros sem distinção de sexo. No entanto, o voto feminino passou a ser obrigatório apenas em 1946. Em consequência dessa participação das mulheres na política enquanto eleitoras, e da visibilidade que passaram a construir a partir de então, ficou garantido em lei, apenas em 1995, uma taxa mínima de participação feminina nas eleições:

Em 29 de setembro de 1995, foi aprovada a Lei n. ${ }^{\circ}$ 9.100, que estabeleceu as normas para a realização das eleições municipais do ano seguinte, e determinou uma cota mínima de 20\% para as mulheres. 6 Em 1997, após esta primeira experiência eleitoral com cotas, a Lei n. ${ }^{\circ}$ 9.504, estende a medida para os demais cargos eleitos por voto proporcional - Câmara dos Deputados, Assembleias Legislativas Estaduais e Câmara Distrital - e altera o texto do artigo, assegurando, não mais uma cota mínima para as mulheres, mas uma cota mínima de 30\% e uma cota máxima de 70\%, para qualquer um dos sexos (GROSSI;MIGUEL, 2001, p. 169).

Apesar de dar visibilidade e garantir espaço para candidatura de mulheres, a lei não tem dado conta de resolver esta disparidade na política, já que a maioria dos candidatos continuam sendo do gênero masculino, abrindo espaço ainda para candidaturas de aparência, nas quais as mulheres são escolhidas apenas para cumprir esse quesito formal e não impedir o partido de lançar candidatos homens na disputa - os quais, em muitos casos, são preferidos pelos eleitores 
e eleitoras. Todos esses elementos evidenciam algumas das dificuldades existentes no processo de construção da representatividade feminina na política. Considerando essa participação da mulher, e tomando como ponto de partida as eleições de 2018 para a Assembleia Legislativa do Estado do Paraná, buscamos, neste trabalho, evidenciar alguns elementos que compõem a campanha destas candidatas. Por percebermos na religião um espaço fértil de promoção eleitoral, conforme já identificado em outros trabalhos, nosso recorte enfoca, portanto, as candidatas evangélicas - que declararam explicitamente seu vínculo religioso - concorrentes no referido pleito.

As relações entre religião e política têm suscitado articulações nos momentos de eleição no Brasil, quando os candidatos se colocam como representantes de Igrejas, de denominações e/ou de valores ligados à moral religiosa. Nesse sentido, o campo eleitoral tem sido palco para manifestações de fé e defesa de pautas que demarcam o estreitamento dessas relações na contemporaneidade(ORO, 2012; NOVAES, 2012; MACHADO, 2003).

De modo geral, os políticos buscam construir sua imagem a partir de elementos diversos, no intuito de convencer o eleitorado, validar suas pautas se sua campanha, justificando sua candidatura a partir de determinada causa que fundamentaria a importância de sua eleição. Para entender as diferentes formas de utilização de elementos religiosos pelos candidatos durante a campanha, Oro (2017) afirma que o "religioso político se contrapõe ao político religioso ou político laico, cujo pertencimento religioso não é explícito ou não interfere diretamente em sua atuação política”. Para os religiosos políticos, em muitos contextos, as pautas de campanha estão vinculadas à moral religiosa, como o aborto e ideologia de gênero, que, por meio desses agentes, acaba por adentrar o campo político (ORO; JÚNIOR, 2015; BURITY, 2011; MEZZOMO; PÁTARO; BONINI, 2014).

Nesta perspectiva, as eleições se tornam palco para um processo com intensidades diversas e distintas formas de apropriações do campo político sobre o campo religioso, sobretudo no movimento de campanha dos candidatos. Assim,

Longe de ser um processo unilateral e unívoco, a relação entre Estado, esfera pública e as religiões no Brasil comporta tanto iniciativas de forças laicistas no sentido de reverter presenças religiosas no Estado consolidadas ao longo dos anos, quanto de novas ações provenientes das religiões de se apropriar de espaços ainda não ocupados no domínio público, ambos ao mesmo tempo e de forma contraditória (CAMURÇA, 2017, p. 860). 
A pluralidade de relações entre religião e política no Brasil tem, de certo modo, permitido um mosaico de configurações que evidenciam contradições, conflitos, negociações e acordos que se dão na interação entre laicos e religiosos, de acordo com concepções e interesses próprios, que expressam diferentes modos de se pensar a laicidade no país. Neste sentido, ao mesmo tempo em que um grupo defende a laicidade do Estado e por isso o afastamento entre religião e política, frentes e representantes religiosos têm visto na política uma oportunidade de lutar por suas causas no meio público, de defender e garantir seus interesses.

Fundamentado nas afirmações até aqui construídas, analisaremos o cenário das eleições à ALEP em 2018, na tentativa de estabelecer intersecções entre a candidatura de mulheres, política e religião, bem como a pluralidade de usos dos elementos religiosos pelas candidatas. Posteriormente buscaremos verificar como essas candidatas construíram suas campanhas, quais pontos são recorrentes, e como os elementos religiosos são incorporados durante a campanha.

Para tanto, faremos uma breve introdução da participação das mulheres nas eleições para deputado estadual no Paraná em 2018, levantando em conta o número total de candidatas e votos recebidos, para então analisarmos as campanhas construídas por algumas delas. Nosso corpus empírico foi produzido a partir do acompanhamento de postagens na rede social Facebook, já que as mídias digitais têm se tornado importantes disseminadoras de informação, sendo local estratégico para a campanha política, utilizada pelos candidatos para construir uma interação com seus eleitores (OLIVEIRA;LEAL;PEREIRA, 2016).

\section{MULHERES RELIGIOSAS NA POLÍTICA: O CENÁRIO DAS ELEIÇÕES DE 2018 PARA A ALEP}

A história das mulheres tem sido marcada por estereótipos que as limitam a atividades domésticas, longe de qualquer posição de poder ou de comando na sociedade, criando uma resistência de representação das mulheres em diferentes espaços, dentre os quais o da política que, assim como exemplifica Perrot (2012), se destaca como uma fronteira difícil de ser superada pelas mulheres:

De todas as fronteiras, a da política sempre foi, em todos os países, a mais difícil de transpor. Como a política é o centro da decisão e do poder, era considerada o apanágio e o negócio dos homens. A polis grega exclui mulheres, tal como os escravos e os bárbaros, mas de maneira diferente (PERROT, 2012, p. 151). 
Assim, a partir do que nos afirma a autora, podemos compreender que o preconceito e a falta de confiança nas mulheres para que ocupem espaços importantes e decisivos na sociedade interferem diretamente na abertura para participação destas no campo político, já que historicamente o gênero feminino sofreu um processo de exclusão nos mais diversos espaços sociais.

Em 2018 no Paraná, do total de 766 candidatos que concorreram a 54 cadeiras para a Assembleia Legislativa do Estado (ALEP), tivemos a candidatura de 238 mulheres, o que caracteriza $31 \%$ do total de candidatos no referido pleito ao legislativo estadual, cumprindo apenas a cota determinada pela lei n. ${ }^{\circ} 9.504$ de 1997.

Gráfico 02: Total de candidatos à ALEP nas eleições de 2018

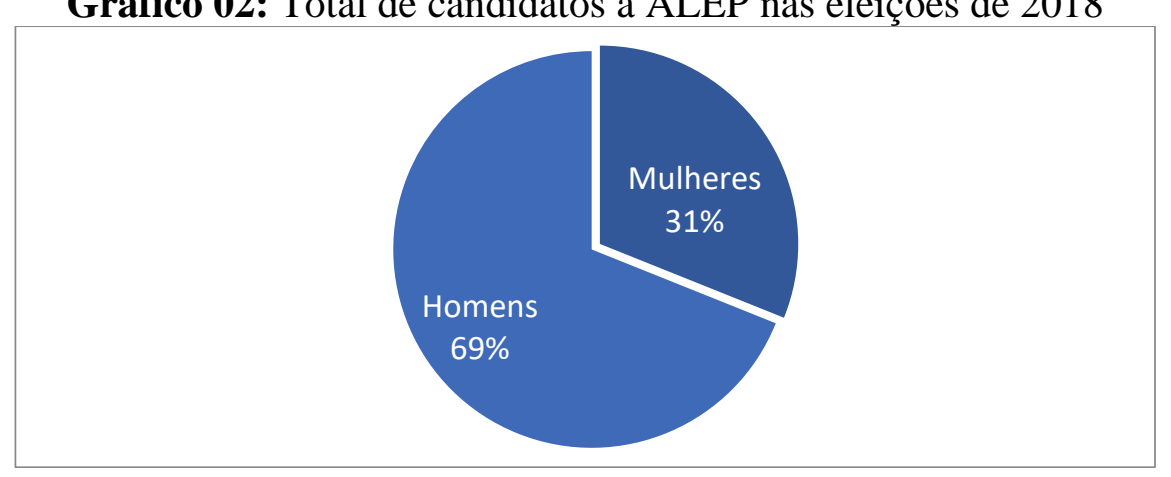

Fonte: Dados da pesquisa

Decorrente deste cenário, percebemos que a quantidade de votos que grande parte destas candidatas recebeu pode ser considerada relativamente baixa, se compararmos à quantidade de votos que receberam as então candidatas eleitas: Maria Victoria Borghetti Barros (50.414 votos), Isabel Cristina Rauen Silvestri (48.805 votos), Mabel Cora Canto (35.036votos), Luciana Guzella Rafagnin (30.931 votos) e Cantora Mara Lima, que ficou inicialmente como suplente, com 33.866 votos, mas assumiu uma das vagas logo no início do mandato. O gráfico abaixo nos permite analisar melhor esses dados:

Gráfico 02 - Margem de votos recebidos pelas candidatas à ALEP 


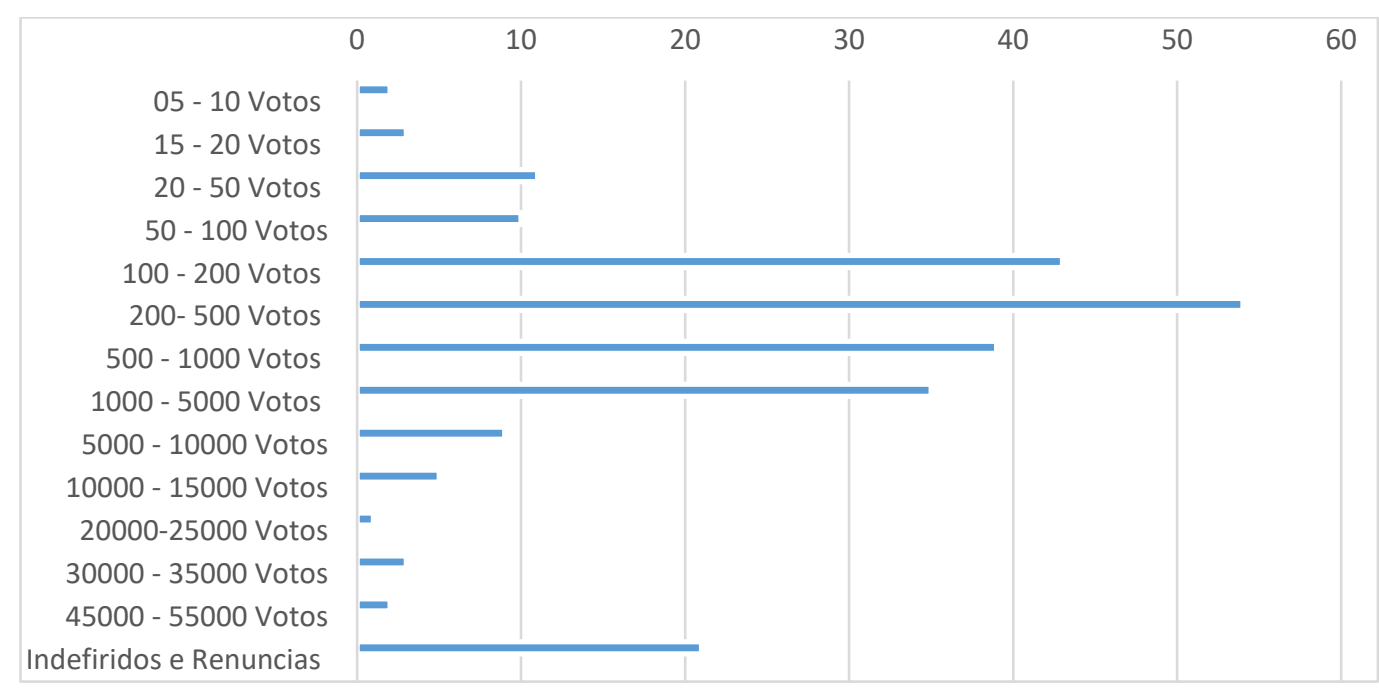

Fonte: Especiais Gazeta - Eleições

Nas eleições de 2018 à ALEP, como podemos verificar, apenas 20 das 238 candidatas alcançaram mais de 5000 votos, enquanto a maior faixa de recorrências, compreendendo 23\% das pleiteantes, receberam entre 200 e 500 votos válidos. A mesma disparidade de votos pode ser identificada ao verificarmos a situação geral de votação no estado do Paraná, considerando que, do total de votos válidos, 5.696.515, ${ }^{4}$ as mulheres receberam no total 263.574 votos, o que corresponde a apenas 5\% do total de votos válidos.

Do total de 238 candidatas mulheres, mediante o acompanhamento de postagens na rede social Facebook, identificamos 10 candidatas que fizeram uso recorrente de elementos e valores religiosos durante o período oficial de campanha, de 20 de Julho a 08 de Outubro de 2018, as quais são apresentadas no quadro a seguir:

Quadro 1: Relação de candidatas que fizeram uso de elementos religiosos durante a campanha eleitoral à ALEP em 2018.

\begin{tabular}{|l|r|r|r|r|r|}
\hline \multicolumn{1}{|c|}{ Nome de Urna } & Número & N. Votos & \multicolumn{1}{c|}{ Situação } & \multicolumn{1}{c|}{ Religião } & \multicolumn{1}{c|}{ Partido } \\
\hline Alexsandra Barroso & 17887 & 2.330 & Não foi eleita & Evangélica & PSL \\
\hline Cantora Mara Lima & 20123 & 33.866 & Suplente & Evangélica & PSC \\
\hline Carla Pimentel & 20007 & 8.495 & Não foi eleita & Evangélica & PSC \\
\hline Claudia Pereira & 20111 & 22.428 & Não foi eleita & Evangélica & PSC \\
\hline Cleusa Camargo & 23213 & 357 & Não foi eleita & Católica & PPS \\
\hline Doutora Malu Viel & 17122 & 3.392 & Não foi eleita & Católica & PSL \\
\hline
\end{tabular}

\footnotetext{
${ }^{4}$ Dados retirados da apuração de votos disponíveis em: https://g1.globo.com/politica/eleicoes/2018/pr/apuracao/governador.ghtml. Acesso em 25 mar. 2019.
} 


\begin{tabular}{|l|r|r|r|r|r|}
\hline Dra. Andreza Albuquerque & 55300 & 11.166 & Não foi eleita & Evangélica & PSD \\
\hline Noemia Rocha & 15007 & 10.442 & Não foi eleita & Evangélica & MDB \\
\hline Pastora Tatiane Galvão & 10600 & 285 & Não foi eleita & Evangélica & PRB \\
\hline Vandeli Lima & 11911 & 356 & Não foi eleita & Evangélica & PP \\
\hline
\end{tabular}

Fonte: Dados da pesquisa

Das 10 candidatas identificadas, 2 são católicas e 8 evangélicas, sendo que, juntas, somam 55.474 votos, o que compreende $17 \%$ do total de votos obtidos pelas mulheres na eleição de 2018 para o cargo de Deputado Estadual do Paraná. A seguir, analisaremos de modo mais aprofundado os materiais de campanha de tais candidatas religiosas, compostos por fotos, imagens, vídeos e publicações, sejam elas originais ou compartilhadas, e que traziam elementos religiosos. No total, foram aproximadamente 1445 materiais, que foram identificados, tabulados e organizados pela pesquisa, e que evidenciam a relação religião e política na campanha das candidatas aqui analisadas.

\section{O USO DE ELEMENTOS RELIGIOSOS NA CAMPANHA: EXEMPLOS DAS CANDIDATAS À ALEP 2018}

Dentre as recorrências dos perfis analisados, pudemos identificar diferentes formas de relação entre religião e política nas campanhas, não sendo possível afirmar acerca de um único modo de fazer política pelas mulheres religiosas. Um dos aspectos que aparece com frequência são as visitas em igrejas e templos religiosos para receber orações e benção para a campanha, legitimando a candidatura pela fé. Outro elemento presente nos materiais de campanha é a defesa de valores cristãos, como a defesa da vida contra a legalização do aborto e a "ideologia de gênero”, e a favor dos ensinamentos cristãos e da valorização da família. Em terceiro lugar, identificamos o uso de elementos e mensagens religiosas que subsidiam e acompanham a propaganda veiculada durante as campanhas. Na sequência, apresentaremos os materiais de campanha que evidenciam cada uma dessas estratégias. Antes, porém, é pertinente destacar que tais formas e elementos aqui mencionados se fazem presentes também na campanha de candidatos homens que utilizam a religião como fundamento de sua candidatura (MACHADO, 2006; GIUMBELLI, 2008).

Como já mencionado, a primeira estratégia que pudemos identificar e que aparece de modo recorrente diz respeito à visita das candidatas em instituições religiosas, onde recebem 
apoio de lideranças que colocam em conexão os anseios políticos da candidata, da igreja e dos fiéis (PRANDI; SANTOS; BONATO, 2019). Na imagem a seguir, apresentamos alguns dos materiais que evidenciam tais ações:

Imagem 01: Visita a igrejas

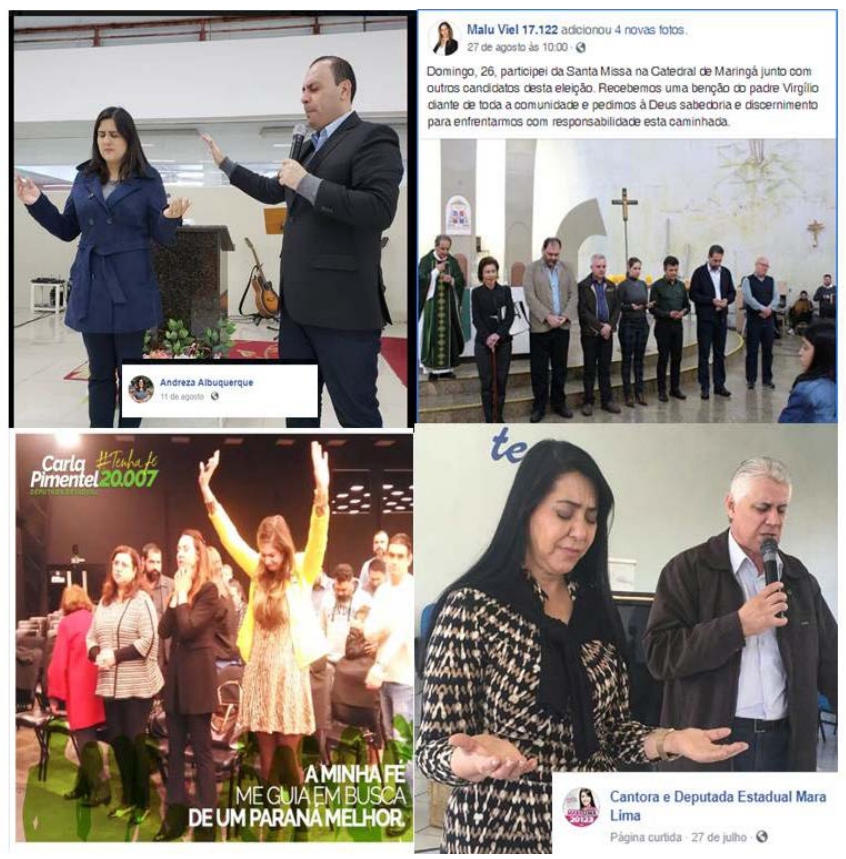

Fonte: Dados da pesquisa

A visita das candidatas Andreza Albuquerque, Malu Viel, Carla Pimentel e Mara Lima em igrejas, orando e recebendo orações de pastores durante a campanha, demonstra a importância da religião em suas candidaturas, ao passo que utilizam-se da fé para legitimar e ganhar força no campo político, expressando que, mais do que sua vontade em ser candidatas, está a vontade de Deus sobre elas.

Em segundo lugar, também pudemos verificar a defesa de pautas que reforçam uma ordem moral e social conservadora, a qual, segundo as religiosas políticas, estaria sendo atacada e destruída pelo movimento de secularização (MARIANO, 2016).

Imagem 02: Defesa de valores religiosos 


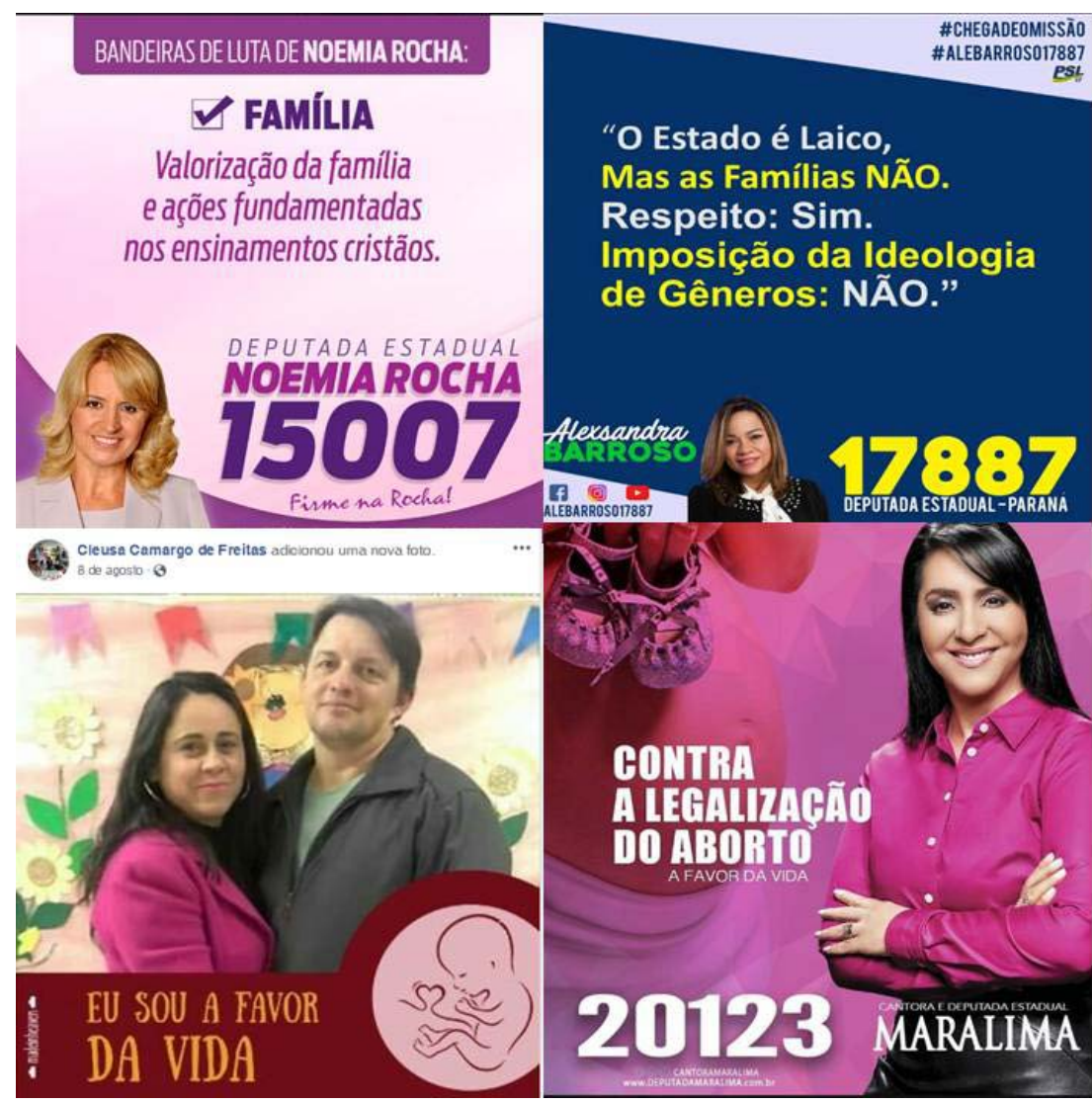

Fonte: Dados da pesquisa

As candidatas Noemia Rocha, Alessandra Barroso, Cleusa Camargo e Mara Lima colocam sua imagem, nome e número de urna em materiais de campanha que destacam posicionamentos geralmente ligados às ideologias religiosas, colocando-se contra o aborto e a “ideologia de gênero”, reforçando a valorização da família e do ensinamento de valores cristãos.

Por fim, outro elemento comum às campanhas foi a utilização de símbolos e mensagens religiosas que ligassem diretamente a imagem da candidata à religião, delimitando características que constituem um sistema de representação com modelos de comportamento e organização próprias da cultura religiosa (RANQUETAT JR, 2012).

Imagem 03: Uso de símbolos ou mensagens religiosas 

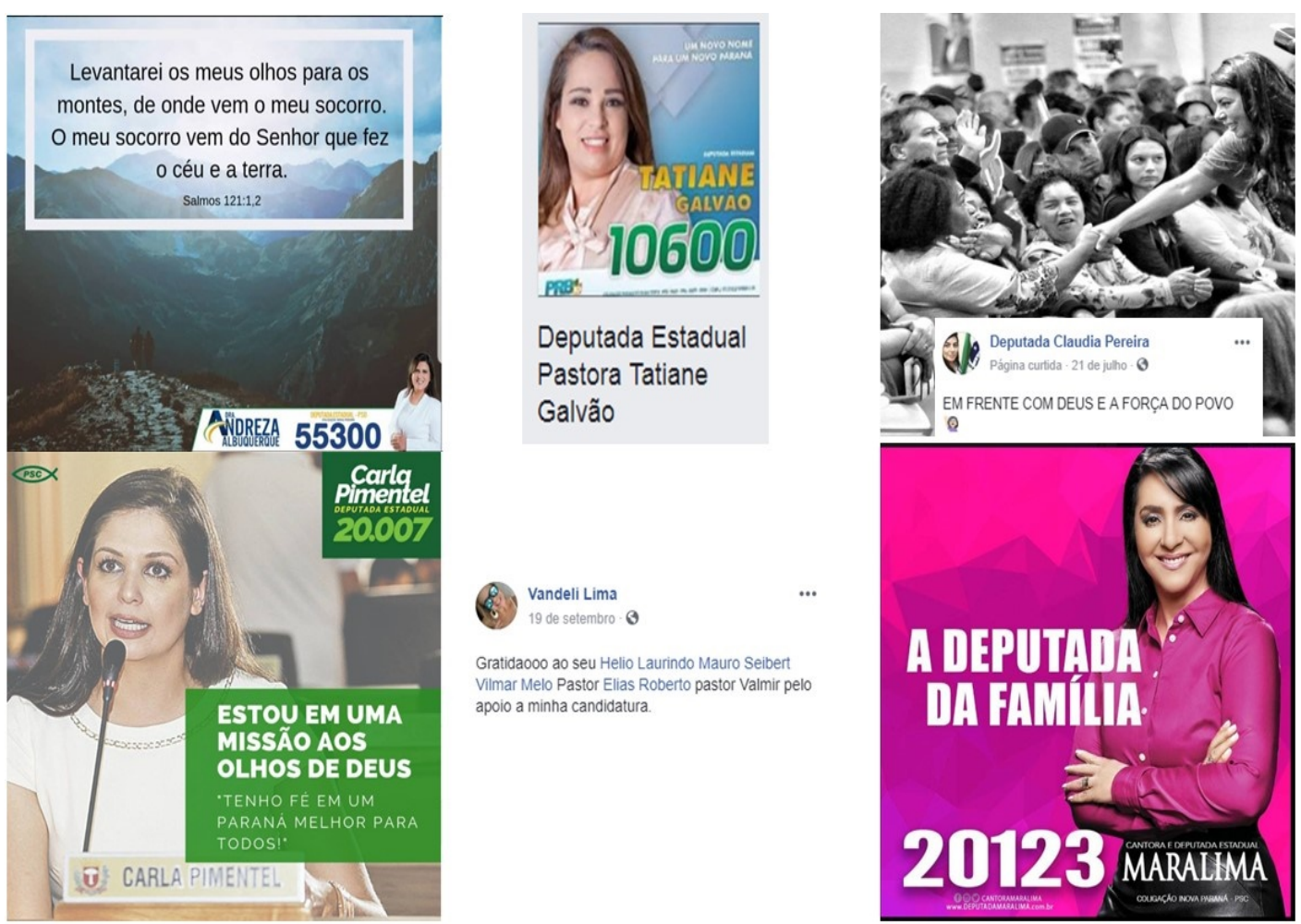

Fonte: Dados da pesquisa

No que diz respeito ao uso de elementos religiosos, destacamos o caso de Vandeli Lima, que destaca o apoio recebido de pastores para sua candidatura, além do uso de versículos bíblicos em material de campanha com nome de urna e número da candidata Andreza Albuquerque. Especificamente nos casos das candidatas Carla Pimentel e Claudia Pereira, a participação na disputa eleitoral é posta como uma missão ou bênção de Deus. Já no caso de Tatiane Galvão, fica exemplificado o uso da titulação religiosa de pastora, enquanto Mara Lima se coloca como a deputada da família.

Refletindo acerca dos exemplos acima, percebemos diferentes configurações de elementos religiosos ligados ao campo político, para promover as candidatas ligados a diferentes denominações religiosas, mas que sobretudo estão ligadas pelos valores morais cristãos que passam a se constituir como pauta na esfera do poder público.

\section{CONSIDERAÇÕES FINAIS}

Considerando as dificuldades que as mulheres encontram para adentrar e manter-seno campo político, identificamos em algumas candidaturas uma relação de poder que vai além da 
divisão de gênero, sendo utilizada como estratégia a recorrência ao campo religioso para legitimar a presença das mulheres na política, já que sua participação é muitas vezes desacreditada e despercebida pela sociedade, que desconhece o processo histórico pelo qual as mulheres passaram e ainda passam para garantir seu espaço na cena pública.

Dentre as pautas escolhidas para compor as estratégias de campanha, as candidatas aqui mencionadas vêem na religião um espaço fértil de proposições e eleitorado, colocando-se como candidatas cristãs e que, por isso, defendem e valorizam sua moral e seus ensinamentos, sendo contra qualquer tipo de "ameaça" que coloque em risco os valores religiosos. Por isso, são candidatas da chamada família tradicional cristã, contra a legalização do aborto e contra a ideologia de gênero, em alguns casos defendendo o ensinamento de princípios cristãos nas escolas. De todo modo, apesar de estarem mencionadas aqui como o conjunto de mulheres que se destacaram pelo uso de elementos religiosos na campanha, não foi possível identificar um único modo de fazer política pelas mulheres, ou uma mesma forma de recorrência e de uso desses elementos, já que um mesmo símbolo pode ser usado de diferentes maneiras por cada candidata, não havendo, ainda, pautas específicas voltadas para as mulheres. Outro elemento que nos parece relevante é o fato de as campanhas apresentadas por estas mulheres religiosas serem muito semelhantes àquelas conduzidas pelos candidatos homens vinculados à religião, de modo que não é possível verificar, a partir dos materiais analisados, elementos próprios do gênero feminino nas estratégias de utilização do imaginário religioso na campanha eleitoral.

Por fim, o que podemos sinalizar como recorrente é o pequeno número de votos alcançados pelas candidatas, se comparado aos votos recebidos pelos candidatos homens, revelando que, mesmo depois de adentrarem no campo político, as mulheres parecem ainda encontrar dificuldades para se elegerem. Faz-se necessário, também, nos atentarmos para a quantidade de mulheres candidatas e a quais propósitos atendem tais candidaturas: estão na cena pública para representar o gênero feminino, as pautas feministas, pautas religiosas ou política públicas justas e necessárias, ou apenas para cumprir a cota exigida em lei? Este questionamento, levantado no início deste texto a partir das manchetes que nos chamam atenção sobre as candidaturas laranjas de mulheres no Brasil, reflete, em parte, o cenário das eleições de 2018 no Paraná, que contou com 30\% de pleiteantes mulheres, exatamente o quantitativo exigido pela lei de cotas de gênero. Vale destacar ainda a quantidade de votos recebidos e de 
candidatas eleitas que nos faz, mais uma vez, questionar tal participação, que, apesar de aparente, parece enfrentar dificuldades em obter efetivação eleitoral e representativa.

\section{REFERÊNCIAS BIBLIOGRÁFICAS}

CAMURÇA, Marcelo Ayres. A questão da laicidade no Brasil: mosaico de configurações e arena de controvérsias. Horizonte, Belo Horizonte, v. 15, n. 47, jul./set. 2017.

GIUMBELLI, Emerson. A presença do religioso no espaço público: modalidades no Brasil. In: Revista Religião e Sociedade, Rio de Janeiro, 28, 2 (2008): 80-101.

GROSSI, M. P.; MIGUEL, S. M. Transformando a diferença: mulheres na política. Revista Estudos Feministas, Florianópolis, v. 9, n.1, p. 167-206, 2001.

CARVALHO JUNIOR, Erico Tavares de; ORO, Ari Pedro.Eleiçõesmunicipais2016:religiãoepolíticanascapitaisbrasileiras.Debates do NER, Porto Alegre, ano 18, n. 32, p. 15-68, jul./dez. 2017.

MACHADO, Maria das Dores. Existe um estilo evangélico de fazer política? In: BIRMAN, Patrícia (Org.). Religião e espaço público. São Paulo: Attar, 2003, p. 283-307.

2006.

. Política e religião: a participação dos evangélicos nas eleições. Rio de Janeiro: FGV,

MARIANO, Ricardo. Expansão e ativismo político de grupos evangélicos conservadores: secularização e pluralismo em debate.Civitas, Porto Alegre, v. 16, n. 4, p. 710 -28, 2016.

MEZZOMO, Frank Antonio; PÁTARO, Cristina Satiê de Oliveira; BONINI, Lara de Fátima Grigoletto. Religião e política nas eleições ao legislativo municipal de Campo Mourão/PR.Debates do NER, Porto Alegre, v. 1, n. 25, 2014.

NOVAES, Regina. Juventude, religião e espaço público: exemplos “bons para pensar” tempos e sinais. Religião e Sociedade, Rio de Janeiro, v. 31, n. 1, p. 184-208, 2012.

OLIVEIRA, Luiz Ademir de; LEAL, Paulo Roberto Figueira; PEREIRA, Carolina Lima Silva. A disputa eleitoral no ciberespaço: uma análise das estratégias dos candidatos a deputado federal nas fanpages. Lumina, Juiz de Fora, v. 10, n. 1, p. 1-19, abr. 2016.

ORO, Ari Pedro; JUNIOR, Erico Tavares de Carvalho. Eleições gerais de 2014: religião e política no Rio Grande do Sul. Debates do NER, Porto Alegre, ano 16, n. 27, p. 145171,jan./jun. 2015. 
ORO, Ari Pedro. Liberdade religiosa no Brasil: as percepções dos atores sociais. In: ORO, Ari Pedro; STEIL, Carlos Alberto; CIPRIANI, Roberto; GIUMBELLI, Emerson (Orgs.). A religião no espaço público: atores e objetos. São Paulo: Terceiro Nome, 2012, p. 181-193.

PRANDI, Reginaldo;SANTOS, Renan William dos;BONATO, Massimo. Igrejas evangélicas como máquinas eleitorais no Brasil.Revista USP, São Paulo, n. 120,p. 43-60, 2019.

PERROT, Michelle. Minha história das mulheres. 2.ed.São Paulo: Contexto, 2012.

RANQUETAT JR., César Alberto. A presença da Bíblia e do crucifixo em espaços públicos no Brasil: religião, cultura e nação. ORO, Ari Pedro; STEIL, Carlos Alberto; CIPRIANI,Roberto; GIUMBELLI, Emerson (Orgs.). A religião no espaço público: atores e objetos. São Paulo: Terceiro Nome, 2012. 